\title{
Synthesis and characterisation of new copper(II) coordination polymers constructed from pyrazine-tetrazole ligands with the formation of a water cluster
}

\author{
Ursula Sheridana, John F. Gallagher ${ }^{b}$, Elisa Fadda ${ }^{a}$, Morten J. Bjerrumª and John McGinleyc \\ aDepartment of Chemistry, Maynooth University, County Kildare, Ireland; bSchool of Chemical Sciences, Dublin City University, Dublin 9, Ireland; \\ 'Department of Chemistry, University of Copenhagen, Copenhagen, Denmark
}

\section{ABSTRACT}

Three novel bis-tetrazole ligands (1-3) containing carboxylate functional groups on the tetrazole rings and a rigid pyrazine linker unit, for the construction of coordination polymers when coordinated to copper(II) ions, were synthesised and structurally characterised. The use of pyrazine as a rigid linker between the two tetrazole units was expected to increase the dimensionality of the solid phase polymeric network of the resulting copper(II)-containing compounds. X-ray structures of the ligands revealed the effect of the substitution position on the tetrazole ring of the ester/ carboxylate groups. Higher solid phase dimensionality was successfully achieved as shown by the layered two-dimensional (2-D) coordination structure being formed when the pyrazine bis-tetrazole systems were reacted with copper(II) chloride, although not in the expected manner. There was no interaction between the pyrazine nitrogen atoms and the metal ion. Computational studies showed that this was probably due to the geometry, required by the copper ion, to be involved in the close packing between the layers. The 2-D coordination polymer based on the asymmetric substituted pyrazine bis-tetrazole, $\left[\mathrm{Cu}(4)\left(\mathrm{H}_{2} \mathrm{O}\right)\right]\left(\mathrm{H}_{2} \mathrm{O}\right)_{2}$, was further connected into a three-dimensional (3-D) coordination network through hydrogen bonding between $\mathrm{H}_{2} \mathrm{O}$ molecules. These $\mathrm{H}_{2} \mathrm{O}$ molecules were connected as a unique 1-D chain throughout the structure.

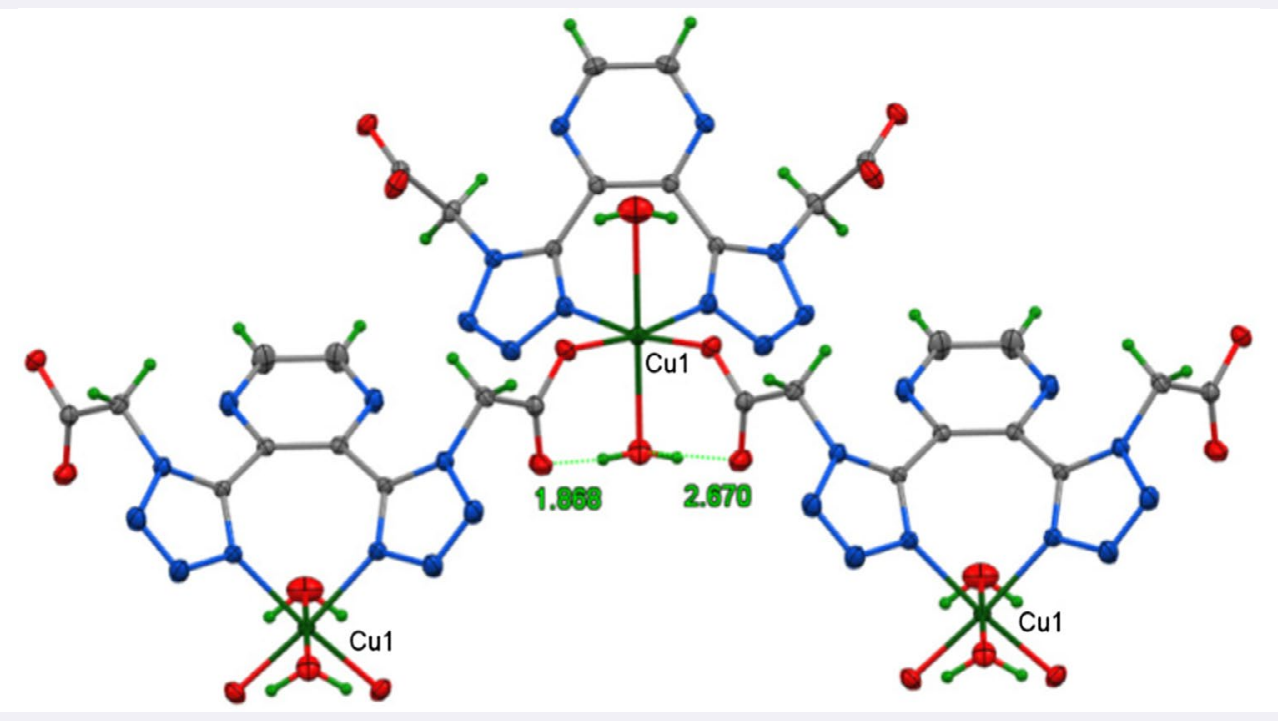

Three novel bis-tetrazole ligands (1-3) containing carboxylate functional groups on the tetrazole rings and a rigid pyrazine linker unit, for the construction of coordination polymers when coordinated to copper(II) ions, were synthesised and structurally characterised.
ARTICLE HISTORY

Received 21 October 2015

Accepted 17 November 2015

KEYWORDS

Tetrazole; $X$-ray structure; coordination polymers 


\section{Introduction}

The use of simple chelating bidentate nitrogen donor compounds, such as 1,10-phenanthroline or 2,2-bipyridine, as ligands in coordination chemistry, and particularly the chemistry of coordination polymers (CPs), is widespread in the literature, with many review articles available covering their resultant use, for example, in the areas of fluorescence, luminescence, medicinal chemistry, catalysis, sensors or DNA interactions $(1,2)$. More recently, the occurrence of CPs, based on bis-tetrazole ligands, in the literature has increased enormously and several bis-tetrazoles with various linkers joining the two heterocycles have been investigated (3). One of the earliest reported examples was the linear 1,4-benzeneditetrazol-5-yl (BDT) ligand employed by Molloy and co-workers in 2000 (4). However, in 2006, research by Long and co-workers identified that carboxylate groups on most commonly used bridging linkers could be replaced by heterocyclic ligands, specifically tetrazoles or tetrazolates (5). This is the case for BDT, with the ability to form analogous porous $\mathrm{CP}$ structures that exhibit reversible $\mathrm{H}_{2}$ uptake with enhanced binding capabilities (5). This research work demonstrated the utility of bis-tetrazole-based ligands for producing robust CPs with permanent porosity, and for possessing topologies mimicking those of carboxylate-based materials.

In our previous work, we successfully designed a series of pyridyl-tetrazole ligands with a flexible tethered carboxylate group and introduced them into CP systems, and obtained novel networks and multinuclear clusters (6). In the present research, we have developed these systems into bis-tetrazole systems, where the linker introduced to join these moieties was a pyrazine moiety, a rigid linker with limited conformational freedom; hence the ligands were synthesised as presented in Scheme 1. In addition, pyrazine nitrogen atoms are well known for their own donor capacities (7), and hence we expected that coordination to the metal ion centres from this moiety could lead to higher dimensionality. To the best of our knowledge, research on these bis-tetrazole ligands in CPs has not been reported to date. Hence, this paper and research represents a novel area of exploration and for further development.

\section{Experimental}

\subsection{Instrumentation}

${ }^{1} \mathrm{H}$ and ${ }^{13} \mathrm{C}$ NMR ( $\delta$ ppm; $\mathrm{J} \mathrm{Hz}$ ) spectra were recorded on a Bruker Avance $300 \mathrm{MHz}$ NMR spectrometer using saturated $\mathrm{CDCl}_{3}$ or $\mathrm{d}_{6}$-DMSO solutions with $\mathrm{Me}_{4} \mathrm{Si}$ reference, unless indicated otherwise, with resolutions of $0.18 \mathrm{~Hz}$ and $0.01 \mathrm{ppm}$, respectively. Infrared spectra $\left(\mathrm{cm}^{-1}\right)$ were recorded as $\mathrm{KBr}$ discs or liquid films between $\mathrm{NaCl}$ plates using a Perkin Elmer System 2000 FT-IR spectrometer. Solution UV-Vis spectra were recorded using

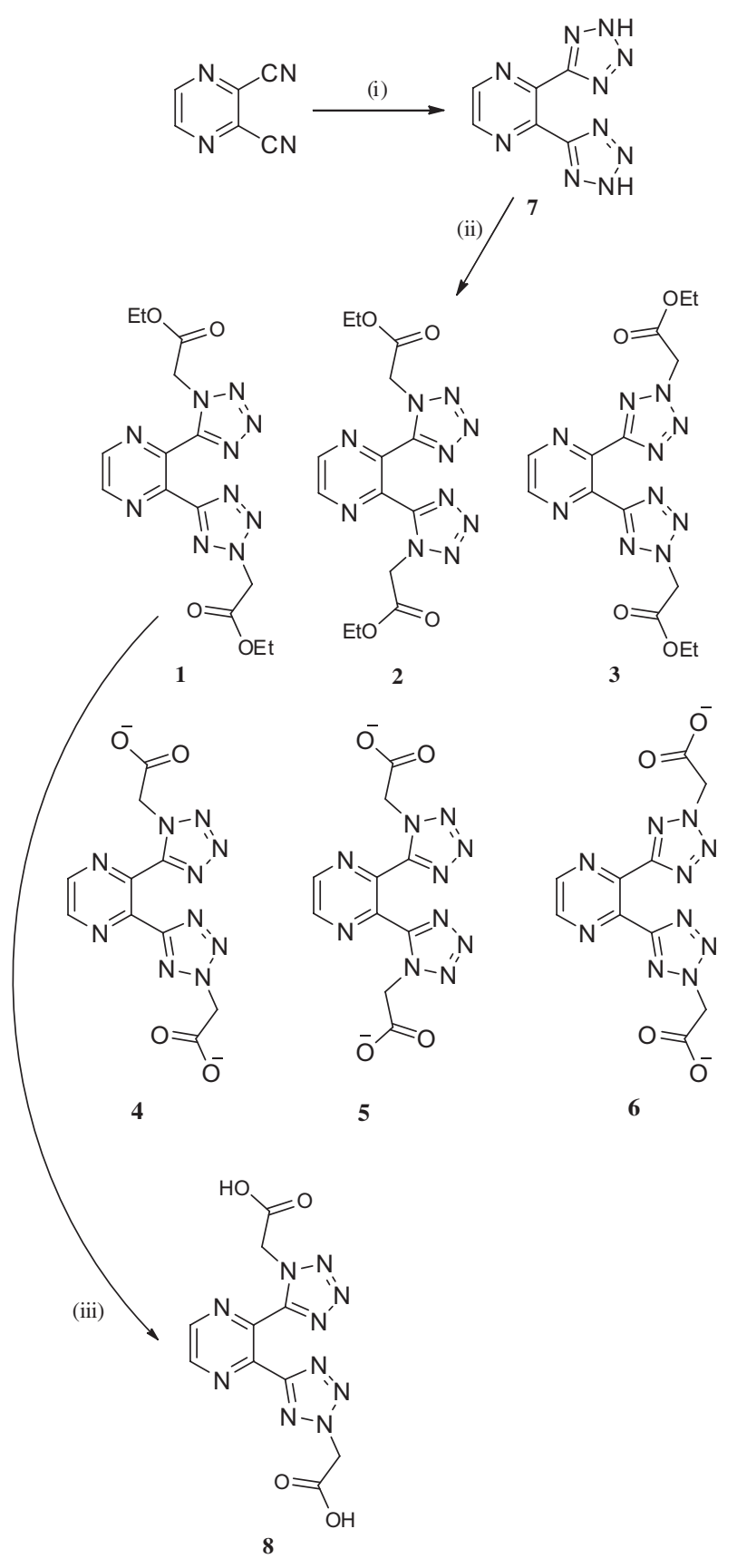

Scheme 1. Ligands (1-6 and 8) as linked by a rigid pyrazine linker, used in this work. Synthetic scheme for the synthesis of 1, 2, 3 and 8. Reagents and conditions: (i) $\mathrm{NaN}_{3}, \mathrm{NH}_{4} \mathrm{Cl}, \mathrm{LiCl}, \mathrm{DMF}, 110^{\circ} \mathrm{C}$, 12 h, 67\%; (ii) DIEA, BrCH $\mathrm{COOEt}_{2} \mathrm{MeCN}, 82^{\circ} \mathrm{C}, 24 \mathrm{~h}, 23 \%$ (1), 10\% (2), 9\% (3); (iii) $\mathrm{NaOH}, \mathrm{EtOH}, \mathrm{HCl}, 80^{\circ} \mathrm{C}, 5 \mathrm{~h}$.

HPLC grade solvents using a Unicam UV 540 spectrometer. Melting point analyses were carried out using a Stewart Scientific SMP 1 melting point apparatus and are uncorrected. Electrospray (ESI) mass spectra were collected on an Agilent Technologies 6410 Time of Flight LC/MS. Compounds were dissolved in acetonitrile:water (1:1) solutions containing $0.1 \%$ formic acid, unless otherwise stated. The interpretation of mass spectra was made with the help of the program 'Agilent Masshunter 
Workstation Software'. Magnetic susceptibility measurements were carried out at room temperature using a Johnson Matthey Magnetic Susceptibility Balance with $\left[\mathrm{HgCo}(\mathrm{SCN})_{4}\right]$ as reference. EPR spectra were recorded on a Bruker Elexsys E500 spectrometer, operated at the Xband and equipped with an Oxford Instruments cryostat. Microanalyses were carried out at the Microanalytical Laboratory of the National University of Ireland Maynooth, using a Thermo Finnigan Elementary Analyzer Flash EA 1112. The results were analysed using the Eager 300 software. Starting materials were commercially obtained and used without further purification. Solvents used were of HPLC grade. Compound 7 has been previously reported (8).

Caution! Nitrogen-rich compounds such as tetrazole derivatives are used as components for explosive mixtures. In our laboratory, the reactions described were run on a few gram scale, and no problems were encountered. However, great caution should be exercised when heating or handling compounds of this type.

\subsection{Synthesis of ligands $1,2,3$ and 8}

$\mathrm{N}, \mathrm{N}$-Diisopropylethylamine (DIEA) $(8.46 \mathrm{~mL}, 48.60 \mathrm{mmol})$ was added to a suspension of 2,3-di( $1 \mathrm{H}$-tetrazol-5-yl)pyrazine $(7,3.50 \mathrm{~g}, 16.20 \mathrm{mmol})$ in $\mathrm{MeCN}(20 \mathrm{~mL})$ and the suspension was heated to reflux for $1 \mathrm{~h}$. After this time, ethyl bromoacetate $(3.95 \mathrm{~mL}, 35.64 \mathrm{mmol}$ ) was added and the reaction was further refluxed for $24 \mathrm{~h}$. The suspension was then cooled to room temperature and filtered. The filtrate was concentrated under reduced pressure. The three regioisomers were separated by recrystallisation of the residue in $\mathrm{CHCl}_{3}$, Pet. Ether and $\mathrm{MeOH}$. Sequential filtration of the filtrate over time yielded the three purified products.

Ethyl 2-(5-(3-(1-(2-ethoxy-2-oxoethyl)-1H-tetrazol-5-yl) pyrazin-2-yl)-2H-tetrazol-2-yl)-acetate (1)

White block crystals $(1.46 \mathrm{~g}, 23 \%) . \mathrm{IR}(\mathrm{KBr}): \nu=2997$, $2953,1757,1745,1470,1443,1417,1406,1373,1350,1300$, 1276, 1249, 1220, 1154, 1101, 1023, 1014, 993, 892, 881, $808 \mathrm{~cm}^{-1}$. ${ }^{1} \mathrm{H} \mathrm{NMR}\left(\mathrm{CDCl}_{3}\right): \delta=8.94(d, 1 \mathrm{H}, J=2.37 \mathrm{~Hz}$, pyzH), $8.80\left(d, 1 \mathrm{H}, J=2.37 \mathrm{~Hz}\right.$, pyz-H), $5.49\left(s, 2 \mathrm{H}, \mathrm{CH}_{2}\right.$-tet), 5.47 $\left(s, 2 \mathrm{H}_{1} \mathrm{CH}_{2}\right.$-tet $), 4.29\left(q, 2 \mathrm{H}, J=7.17 \mathrm{~Hz}, \mathrm{OCH}_{2}\right), 4.19(q, 2 \mathrm{H}$, $\left.J=7.17 \mathrm{~Hz}, \mathrm{OCH}_{2}\right), 1.30\left(t, 3 \mathrm{H}, J=7.14 \mathrm{~Hz}, \mathrm{CH}_{3}\right), 1.20(t, 3 \mathrm{H}$, $\left.J=7.14 \mathrm{~Hz}, \mathrm{CH}_{3}\right)$ ppm. ${ }^{13} \mathrm{C} \mathrm{NMR}\left(\mathrm{CDCl}_{3}\right): \delta=165.1(\mathrm{C}=\mathrm{O})$, $164.5(C=0), 162.1,150.8,145.5,144.1,143.3,139.9,62.9$, 62.6, 53.7, 49.9, 13.9 ppm. ESI-HRMS: calcd. for $\mathrm{C}_{14} \mathrm{H}_{17} \mathrm{~N}_{10} \mathrm{O}_{4}$ $[\mathrm{M}+\mathrm{H}]^{+}$389.1429, found 389.1416.

Diethyl 2,2'-(5,5'-(pyrazine-2,3-diyl)bis(1H-tetrazole-5,1diyl))diacetate (2)

White needle-like crystals $(0.64 \mathrm{~g}, 10 \%)$. IR (KBr): $\nu=2943,1750,1634,1466,1440,1418,1396,1376,1264$, $1231,1147,1094,1031,884,799,772 \mathrm{~cm}^{-1}$. ${ }^{1} \mathrm{H} \mathrm{NMR}\left(\mathrm{CDCl}_{3}\right)$ : $\delta=8.85\left(s, 2 \mathrm{H}\right.$, pyz-H) $, 5.47\left(s, 4 \mathrm{H}_{1} \mathrm{CH}_{2}\right.$-tet $), 4.21(q, 4 \mathrm{H}$,
$\left.J=7.17 \mathrm{~Hz}, \mathrm{OCH}_{2}\right), 1.23\left(t, 6 \mathrm{H}_{1} J=7.17, \mathrm{CH}_{3}\right) \mathrm{ppm} .{ }^{13} \mathrm{C} \mathrm{NMR}$ $\left(\mathrm{CDCl}_{3}\right): \delta=165.1(\mathrm{C}=\mathrm{O}), 150.5\left(\mathrm{CN}_{4}\right), 144.7,140.9,62.7$ $\left(\mathrm{CH}_{2}\right.$-tet), $49.9\left(\mathrm{OCH}_{2}\right), 14.0\left(\mathrm{CH}_{3}\right)$ ppm. ESI-HRMS: calcd. for $\mathrm{C}_{14} \mathrm{H}_{17} \mathrm{~N}_{10} \mathrm{O}_{4}[\mathrm{M}+\mathrm{H}]^{+}$389.1429, found 389.1434.

Diethyl 2,2'-(5,5'-(pyrazine-2,3-diyl)bis(2H-tetrazole-5,2diyl))diacetate (3)

White needle-like crystals $(0.55 \mathrm{~g}, 9 \%)$. IR (KBr): $\nu=2980$, $1745,1416,1371,1341,1233,1075,1017,876 \mathrm{~cm}^{-1} .{ }^{1} \mathrm{H} \mathrm{NMR}$ $\left(\mathrm{CDCl}_{3}\right): \delta=8.90\left(s, 2 \mathrm{H}\right.$, pyz-H), $5.46\left(s, 4 \mathrm{H}_{1} \mathrm{CH}_{2}\right.$-tet $), 4.27$ $\left(q, 4 \mathrm{H}, J=7.1 \mathrm{~Hz}, \mathrm{OCH}_{2}\right), 1.29\left(t, 6 \mathrm{H}, J=7.1 \mathrm{~Hz}, \mathrm{CH}_{3}\right)$ ppm. ${ }^{13} \mathrm{CNMR}\left(\mathrm{CDCl}_{3}\right): \delta=164.6(\mathrm{C}=\mathrm{O}), 162.6\left(\mathrm{CN}_{4}\right), 145.0,142.4$, $62.8\left(\mathrm{CH}_{2}\right.$-tet $), 53.5\left(\mathrm{OCH}_{2}\right), 14.0\left(\mathrm{CH}_{3}\right)$ ppm. ESI-HRMS: calcd. for $\mathrm{C}_{14} \mathrm{H}_{17} \mathrm{~N}_{10} \mathrm{O}_{4}[\mathrm{M}+\mathrm{H}]^{+}$389.1429, found 389.1438.

2-(5-(3-(1-(carboxymethyl)-(1 H-tetrazol-5-yl)pyrazin-2yl)-2H-tetrazol-2yl)acetic acid (8)

$1(0.05 \mathrm{~g}, 0.13 \mathrm{mmol})$ and $2 \mathrm{M} \mathrm{NaOH}(0.13 \mathrm{~mL})$ were heated to reflux in $\mathrm{EtOH}(15 \mathrm{~mL})$ for $5 \mathrm{~h}$. On cooling, the solution was then concentrated under reduced pressure. The remaining residue was redissolved in $\mathrm{H}_{2} \mathrm{O}(10 \mathrm{~mL})$ and treated with $1 \mathrm{M} \mathrm{HCl}$. The resulting solid was filtered and dried to yield a white crystalline solid $(8,0.04 \mathrm{~g}, 93 \%)$. IR $(\mathrm{KBr}): \nu=3457,3012,1710,1708,1638,1452,1409,1338$, $1240,1161,1016,821 \mathrm{~cm}^{-1} .{ }^{1} \mathrm{H}$ NMR (d $\mathrm{d}_{6}$-DMSO): $\delta=9.09$ $(d, 1 \mathrm{H}, J=2.4 \mathrm{~Hz}$, pyz-H), $9.04(d, 1 \mathrm{H}, J=2.4 \mathrm{~Hz}$, pyz-H), $5.76\left(\mathrm{~s}, 2 \mathrm{H}, \mathrm{CH}_{2}\right.$-tet), $5.53\left(\mathrm{~s}, 2 \mathrm{H}, \mathrm{CH}_{2}\right.$-tet) ppm. ${ }^{13} \mathrm{C} \mathrm{NMR}\left(\mathrm{d}_{6}\right.$ DMSO): $\delta=167.3(\mathrm{C}=\mathrm{O}), 167.0(\mathrm{C}=\mathrm{O}), 161.4,151.1,146.3$, $145.3,142.2,138.9,53.8,49.4$ ppm. ESI-HRMS: calcd. for $\mathrm{C}_{10} \mathrm{H}_{8} \mathrm{~N}_{10} \mathrm{O}_{4}[\mathrm{M}+\mathrm{H}]^{+} 333.0803$, found 333.0808 .

\subsection{Metal complexation reactions of 1 and 2}

$\left[\mathrm{Cu}(4)\left(\mathrm{H}_{2} \mathrm{O}\right)\right]\left(\mathrm{H}_{2} \mathrm{O}\right)_{2}$

$1(0.10 \mathrm{~g}, 0.26 \mathrm{mmol})$ was suspended in deionised $\mathrm{H}_{2} \mathrm{O}$ $(15 \mathrm{~mL}) . \mathrm{NaOH}(0.02 \mathrm{~g}, 0.52 \mathrm{mmol})$ was added and the mixture was heated under reflux for $2 \mathrm{~h}$. $\mathrm{CuCl}_{2} \cdot 2 \mathrm{H}_{2} \mathrm{O}(0.04 \mathrm{~g}$, $0.26 \mathrm{mmol}$ ) was added in deionised $\mathrm{H}_{2} \mathrm{O}$ and the solution was cooled slowly and allowed to stand for several days. The resulting solids were filtered off and washed with deionised $\mathrm{H}_{2} \mathrm{O}$. Blue crystalline solid (0.07 g, 60\%). $\mathrm{C}_{10} \mathrm{H}_{8} \mathrm{CuN}_{10} \mathrm{O}_{5} \cdot 2 \mathrm{H}_{2} \mathrm{O}$ : calcd. C 26.82, H 2.70, N 31.28\%; found C 26.59, H 2.66, N $31.48 \%$. IR (KBr): $\nu=3419,3001,1660,1636,1480,1433$, $1377,1353,1328,1305,1216,1176,1108,1087,1032,879$, $821,751,718,691,547 \mathrm{~cm}^{-1}$. Magnetic moment: 1.96 B.M.

$\left[\mathrm{Cu}(\mathbf{5})\left(\mathrm{H}_{2} \mathrm{O}\right)_{2}\right]_{\mathrm{n}}$

$2(0.03 \mathrm{~g}, 0.08 \mathrm{mmol})$ was suspended in deionised $\mathrm{H}_{2} \mathrm{O}(6 \mathrm{~mL}) . \mathrm{NaOH}(6 \mathrm{mg}, 0.16 \mathrm{mmol}$ ) was added to the mixture and the reaction was heated under reflux for $2 \mathrm{~h} . \mathrm{CuCl}_{2} \cdot 2 \mathrm{H}_{2} \mathrm{O}(0.03 \mathrm{~g}, 0.16 \mathrm{mmol})$ in deionised $\mathrm{H}_{2} \mathrm{O}$ was added to the solution which was then cooled slowly. A blue crystalline solid was formed $(0.02 \mathrm{~g}, 49 \%)$, which was filtered off and washed with deionised $\mathrm{H}_{2} \mathrm{O}$. $\mathrm{C}_{10} \mathrm{H}_{6} \mathrm{CuN}_{10} \mathrm{O}_{4} \cdot 2 \mathrm{H}_{2} \mathrm{O}$ : calcd. C 27.95, H 2.35, N 32.59\%; found C 28.24, H 3.03, N 32.08\%. IR (KBr): $\nu=3524,3050$, 


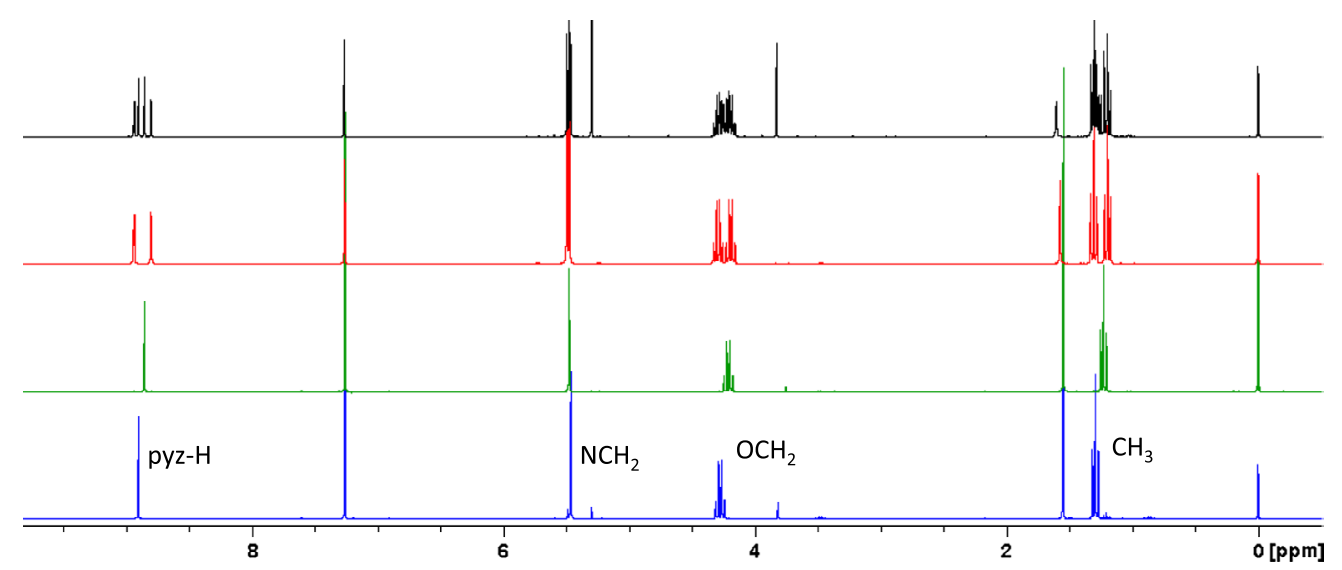

Figure 1. (Colour online) ${ }^{1} \mathrm{H}$ NMR spectra of the crude mixture (black), 1 (red), 2 (green) and 3 (blue) in $\mathrm{CDCl}_{3}$, with some water present at $1.56 \mathrm{ppm}$.

$1640,1452,1422,1380,1304,1149,1125,1101,1032$, $955,889,955,889,819,718,682,590,553,454,384 \mathrm{~cm}^{-1}$. Magnetic Moment: 2.11 B.M.

\subsection{X-ray structure determination}

Single crystal X-ray data collection, data reduction (9), structure solution and refinement $(10,11)$ are as described previously (12). Selected crystallographic and structural information are available on the Cambridge Structural Database (CSD). Molecular and hydrogen bonding diagrams were generated using ORTEP (with displacement ellipsoids drawn at the $30 \%$ probability level) and with atoms as their van der Waals spheres (13). CCDC reference codes 1410736-1410740 and copies available, Email: deposit@ccdc.cam.ac.uk.

\subsection{Computational methods}

All calculations were performed at the RI-UB3LYP/def2-SVP level of theory with v. 6 of TURBOMOLE (14). Stable minima were obtained through the quasi-Newton-Raphson optimisation protocol STATPT implemented in TURBOMOLE. Convergency criteria for both the SCF and the geometry optimisation cycles were set to the default values. Starting structures for the geometry optimisations were taken from the crystal structure, where the copper(II) coordination was modified in the case of the pyrazine-tetrazole chelation site with the academic version of Schrödinger Maestro (15). Two water molecules have been included in all the systems to complete the coordination sphere.

\section{Results and discussion}

\subsection{Synthesis and characterisation of ethyl ester derivatives (1-3) and carboxylic acid derivative (8)}

The synthesis of ligands $\mathbf{1}, \mathbf{2}$ and $\mathbf{3}$ was achieved by the synthetic route shown in Scheme 1. The precursor
2,3-di(1H-tetrazol-5-yl)pyrazine (7) was synthesised from the starting 2,3-pyrazinedicarbonitrile in $67 \%$ yield as an orange crystalline solid. The acquired data $\left(\mathrm{IR},{ }^{1} \mathrm{H}\right.$ and ${ }^{13} \mathrm{C}$ spectra) for $\mathbf{7}$ correlated well with literature values (8). Two signals were observed in the ${ }^{1} \mathrm{H}$ NMR spectrum, namely a singlet at $9.11 \mathrm{ppm}$, due to the protons on the pyrazine ring, and a broad peak at $3.56 \mathrm{ppm}$, which arose due to the $\mathrm{N}-\mathrm{H}$ protons. The ${ }^{13} \mathrm{C}$ spectrum exhibited three signals in the aromatic region at 146.1 and $139.8 \mathrm{ppm}$, associated with the carbon atoms of the pyrazine moiety, and at $153.3 \mathrm{ppm}$, which was attributed to the C-5 of the tetrazole ring.

Alkylation of $\mathbf{7}$ was achieved by reacting $\mathbf{7}$ with DIEA (16) and ethyl bromoacetate in $\mathrm{MeCN}$ at reflux temperature for $24 \mathrm{~h}$. The resulting orange clear solution was reduced in vacuo and washed with water in order to remove excess DIEA. A TLC analysis of the crude mixture revealed three overlapping spots, while the crude ${ }^{1} \mathrm{H}$ NMR spectrum also indicated the presence of three products (Figure 1). Despite using several solvent systems, clear separation of the spots by TLC remained unattainable. Therefore, gradual crystallisation of the three regioisomers was attempted with a mixture of $\mathrm{MeOH}$, petroleum ether (40-60\%) and $\mathrm{CHCl}_{3} .{ }^{1} \mathrm{H}$ NMR spectroscopy of $\mathbf{1}$ indicated the asymmetric nature of this crystalline solid (1) as all signals were split due to this asymmetry (Figure 1 ). The ${ }^{13} \mathrm{C}$ NMR spectrum also had many resonances present, with the tetrazole C- 5 carbons resonating at 162.1 ppm for the $\mathrm{N}-2$ substituted tetrazole and $150.8 \mathrm{ppm}$ for the $\mathrm{N}-1$ substituted tetrazole. Asymmetry was also confirmed by IR spectroscopy as two $v(\mathrm{C}=\mathrm{O})$ vibrational modes were positioned at 1745 and $1757 \mathrm{~cm}^{-1}$. The second crop of white solid that crystallised from this mixture (2), when analysed by ${ }^{1} \mathrm{H}$ NMR spectroscopy, proved to be a symmetrically substituted compound, as evident by the relatively simple ${ }^{1} \mathrm{H}$ NMR spectrum obtained (Figure 1). The position of the alkyl ester on the tetrazole ring was elucidated by analysing the ${ }^{13} \mathrm{C}$ NMR spectrum for $\mathbf{2}$, which had a peak at 

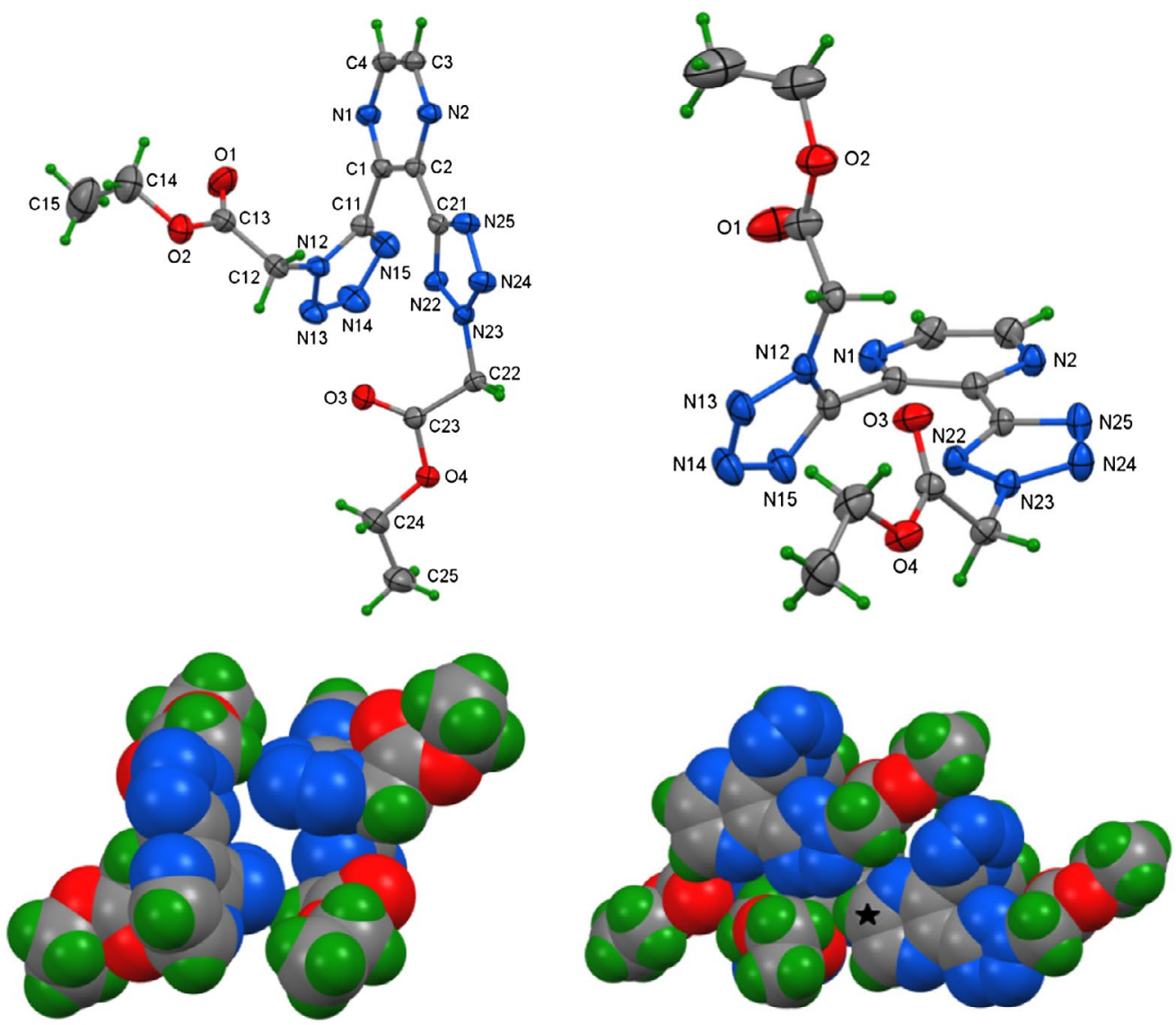

Figure 2. (Colour online) Two ORTEP diagrams of the molecular structure of 1 with non-hydrogen atoms depicted at the $30 \%$ probability level; two CPK diagrams highlight intricate non-classical interactions and bifurcated nature of a $\mathrm{C}-\mathrm{H} \cdots(\mathrm{O}, \mathrm{N})$ interaction $($ as $\star)$.

$150.5 \mathrm{ppm}$ that indicated that compound 2 was the $\mathrm{N}-1, \mathrm{~N}-$ $1^{\prime}$ isomer. The IR spectrum also had a single $\nu(C=O)$ stretch at $1750 \mathrm{~cm}^{-1}$. Isolation of the remaining $\mathrm{N}-2, \mathrm{~N}-2^{\prime}$ isomer (3) proved quite difficult, and only after several recrystallisations was a clean product (3) eventually obtained. The symmetrical nature of the molecule was immediately obvious on analysis of the ${ }^{1} \mathrm{H}$ NMR spectrum, as a singlet integrating for two protons, associated with the pyrazine protons, was observed. A single singlet attributed to the methylene group bonded to the tetrazole ring was also present, as was a quartet integrating for four protons and a triplet integrating for six protons which were attributed to the ethoxy protons. The N-2 substituted nature of the tetrazole rings was confirmed by ${ }^{13} \mathrm{C}$ NMR spectroscopy where the anticipated $\mathrm{C}-5$ of the tetrazole ring was positioned at $162.6 \mathrm{ppm}$. The IR spectrum of $\mathbf{3}$ showed a single $\nu(\mathrm{C}=0)$ vibrational mode positioned at $1745 \mathrm{~cm}^{-1}$.

Single crystals of $\mathbf{1}, \mathbf{2}$ and $\mathbf{8}$ (as a monohydrate derivative) and two copper complexes of ligands $\mathbf{4}$ and $\mathbf{5}$ were analysed by X-ray crystallography and confirmed the structures of the three compounds (see Figures 2-4). Table 1 contains crystallographic data for all five structures as $\mathbf{1 , 2}$, 8, $\left[\mathrm{Cu}(4)\left(\mathrm{H}_{2} \mathrm{O}\right)\right]\left(\mathrm{H}_{2} \mathrm{O}\right)_{2}$ and $\mathrm{Cu}(5)\left(\mathrm{H}_{2} \mathrm{O}\right)_{2}$. In 1, neither of the tetrazole rings are coplanar with the pyrazine ring, with the
$\mathrm{N}-1$ substituted tetrazole ring being especially twisted with respect to the pyrazine ring, forming a dihedral angle of $66.64(7)^{\circ}$ compared to $10.07(7)^{\circ}$ for the $\mathrm{N}-2$ tetrazole ring. This is not unexpected on steric grounds and suggests that the position of the ester substituent in the N-1 substituted tetrazole is greatly hindering the possibility of coplanar systems. Molecules of 1 do not contain strong hydrogen bonding donors, but has several $\mathrm{O}, \mathrm{N}$ acceptor atoms and the crystal structure contains several weaker $\mathrm{C}-\mathrm{H} \cdots \mathrm{O}, \mathrm{N}$ as well as $\pi \cdots \pi$ stacking interactions. A C22-H22B $\cdots \mathrm{N} 14$ interaction that forms hydrogen-bonded dimers about inversion centres is shown in Figure 2(c) and bifurcated $\mathrm{C} 4-\mathrm{H} 4 \cdots \mathrm{O} 1 /$ $\mathrm{N} 24$ interactions in Figure 2(d). Symmetry related atom positions and codes are available in the CIFs (ESI).

The crystal structure of $\mathbf{2}$ is depicted in Figure 3. In comparison to the structure for $\mathbf{1}$, the solid-state structure of $\mathbf{2}$ shows considerable puckering between both tetrazole rings and the pyrazine ring, with the plane of the pyrazine ring and the tetrazole rings forming a dihedral angle of $35.59(15)^{\circ}$ for the $\mathrm{N} 12$ substituted ring and $32.43(18)^{\circ}$ for the N22 substituted ring. As for $\mathbf{1}$, it can be deduced that the substitution at the $\mathrm{N}-1$ position of the tetrazole ring causes a significant amount of steric hindrance between the ortho-related tetrazole rings in these systems. The 



Figure 3. (Colour online) Molecular structure of 2 highlighting the asymmetric nature of the structure and distortion of the tetrazole rings from the plane of the central pyrazine ring with non-H atoms depicted at the $30 \%$ probability level. The CPK view displays the 'slipped' nature of the tetrazole rings with respect to the pyrazine ring and one another, along the direction of the $A$ and $B$ axes.

hydrogen bonding in $\mathbf{2}$ is due to three $\mathrm{C}-\mathrm{H} \cdots \mathrm{N} / \mathrm{O}$ interactions of comparable geometries.

The synthesis of the carboxylic acid derivative (8) was also undertaken (see Scheme 1), in a manner similar to those reported by Yang and Koguro (17). The diester derivative 1 was hydrolysed by employing excess $\mathrm{NaOH}$ in $\mathrm{EtOH}$. The main difference in the ${ }^{1} \mathrm{H}$ NMR spectrum of $\mathbf{8}$ are the peaks representing the ethyl fragment of the ester, present in the ${ }^{1} \mathrm{H}$ NMR spectra of 1-3 as a triplet and a quartet, are no longer observed in the ${ }^{1} \mathrm{H}$ NMR spectrum of 8. The IR spectra of $\mathbf{8}$ supports the NMR data suggesting formation of the carboxylic acid compounds, with the $C=0$ stretching vibration moving from $\sim 1747 \mathrm{~cm}^{-1}$, for the ester compounds, to $1710 \mathrm{~cm}^{-1}$, for the carboxylic acid group.

The crystal structure of $\mathbf{8}$ as a monohydrate derivative is depicted in Figure 4. In comparison to the molecular structure for $\mathbf{1}$, the structure $\mathbf{8}$ shows considerable twisting between both tetrazole rings and the pyrazine ring, with the interplanar plane of the pyrazine ring and the tetrazole rings forming an angle of $31.94(8)^{\circ}$ for the $\mathrm{N} 12$ substituted ring and $68.08(7)^{\circ}$ for the N22 substituted ring. As before, it can be deduced that the substitution at the $\mathrm{N}-1$ position of the tetrazole ring causes a significant amount of steric hindrance in these systems. As $\mathbf{8}$ also contains a molecule 
(a)

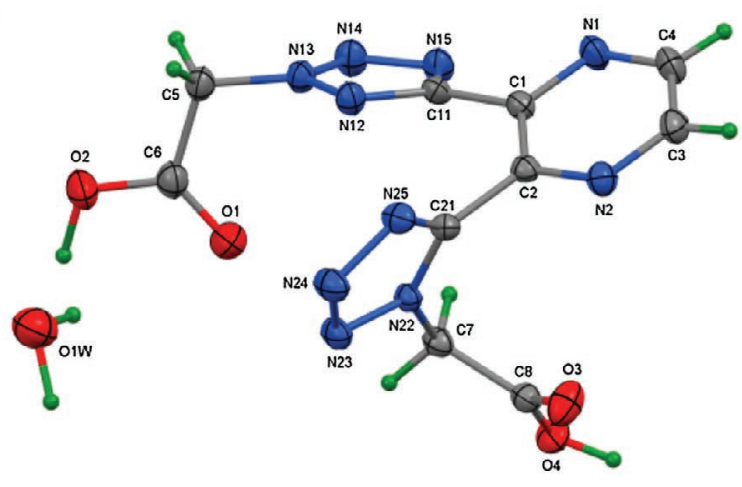

(c)

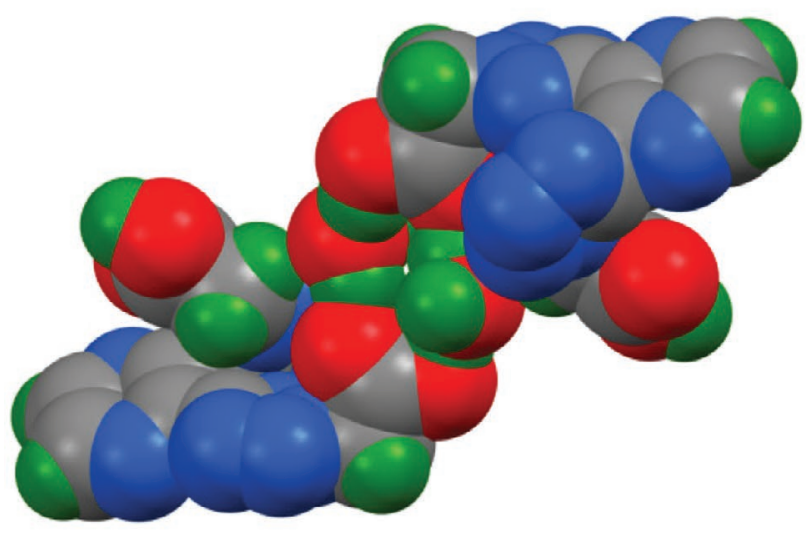

(b)

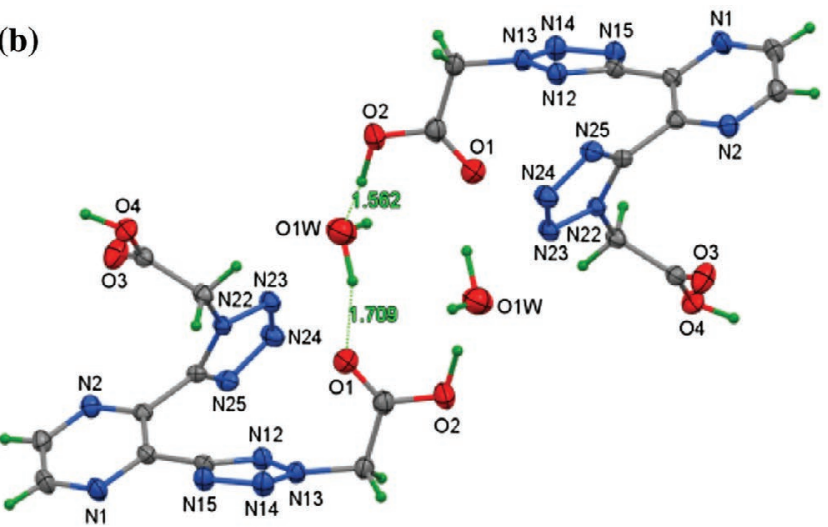

(d)

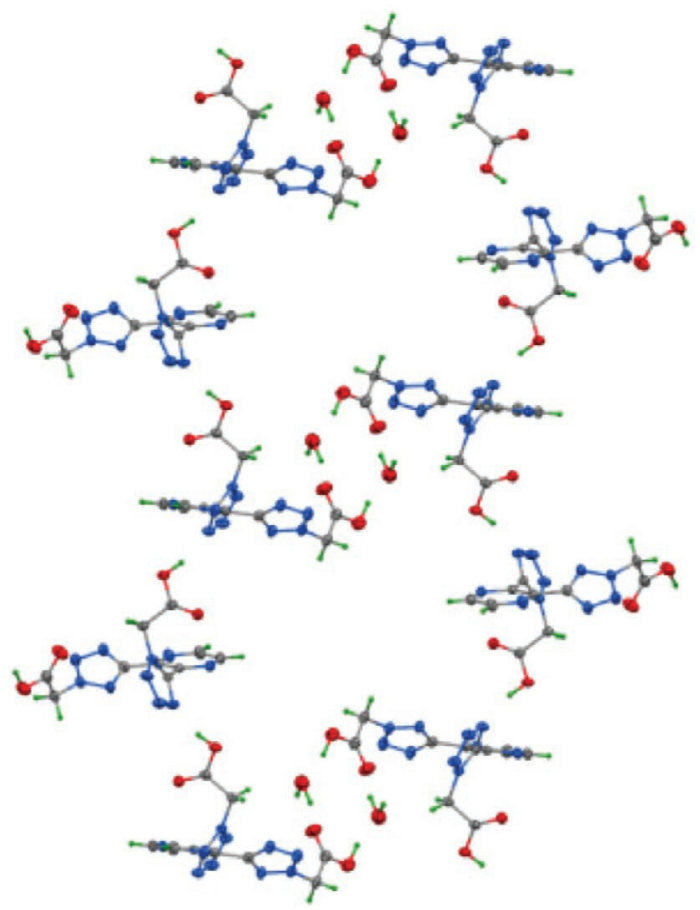

Figure 4. (Colour online) Molecular structure of 8 as a monohydrate in the asymmetric unit and with the dimeric assembly involving two $8\left(\mathrm{H}_{2} \mathrm{O}\right)$ entities as ORTEP and CPK diagrams; the assembly of dimeric units by $\mathrm{COOH}^{\cdots} \mathrm{N}$ interactions.

of water in the unit cell, this plays a key role in assembly as is shown in the diagrams (Figure $4(b)-(d)$ ). Molecules of $\mathbf{8}$ can be considered to assemble as dimers involving two water molecules. Instead of the common cyclic $R^{2}{ }_{2}(8)$ dicarboxylic acid dimer formation, two water molecules are inserted between two carboxylic acids to generate a cyclic ring as $R^{4}{ }_{4}(12)$. Dimers are linked by $\mathrm{COOH} \cdots \mathrm{N}$ hydrogen bonding along the $a$-axis direction forming a 2-D sheet that assembles into a 3-D structure by weaker intermolecular interactions. The structure essentially is generated by the four $\mathrm{O}-\mathrm{H} \cdots \mathrm{O} / \mathrm{N}$ interactions involving the two carboxylic acid $\mathrm{O}-\mathrm{H}$ and two water $\mathrm{O}-\mathrm{H}$ donors with appropriate acceptors. For comparison, the structures of dicarboxylic acid ligands have been studied extensively and are of especial interest when they contain other donor atoms such as -O- (18).

\subsection{Synthesis and characterisation of copper(II) complex of 1}

Ligand 1 was nonsolvothermally converted to $\mathbf{4}$, in situ using aqueous sodium hydroxide. After heating this solution for two hours, $\mathrm{CuCl}_{2} \cdot 2 \mathrm{H}_{2} \mathrm{O}$ was added to the solution and the resulting blue solution was cooled slowly and allowed to stand for several days. Block-shaped royal blue crystals, which had formed after this time, were removed by filtration and dried. The IR spectrum of the blue crystal revealed that no protonated carboxylic acid was present in the structure. Monodentate coordination of the acetate to the copper(II) ion was suggested as a $\nu_{\text {asym }}\left(\mathrm{COO}^{-}\right)$vibration was observed at $1660 \mathrm{~cm}^{-1}$ and the corresponding $\nu_{\text {sym }}\left(\mathrm{COO}^{-}\right)$was positioned at $1377 \mathrm{~cm}^{-1}$, yielding a $\Delta\left(\nu_{\text {asym }}\left(\mathrm{COO}^{-}\right)-\nu_{\text {sym }}\left(\mathrm{COO}^{-}\right)\right)$value of $283 \mathrm{~cm}^{-1}$ 
(19). A broad strong stretch positioned at $3419 \mathrm{~cm}^{-1}$ indicated the possible coordination of water molecules. Elemental analysis of the blue solid suggested the compound was $\left[\mathrm{Cu}(4)\left(\mathrm{H}_{2} \mathrm{O}\right)\right]\left(\mathrm{H}_{2} \mathrm{O}\right)_{2}$, which confirmed that the ester groups had been removed from $\mathbf{1}$ to produce $\mathbf{4}$ in the complex.

\subsection{Crystal and molecular structures and a unique water cluster in $[\mathrm{Cu}(4)(\mathrm{H} 2 \mathrm{O})](\mathrm{H} 2 \mathrm{O})_{2}$}

The single crystals obtained were analysed by X-ray crystallography and resulted in an unexpected and interesting structure (Figure 5). There are two crystallographically independent copper(II) complexes in the asymmetric unit and each copper(II) centre possesses a square pyramidal geometry. The two copper(II) fragments in the asymmetric units are labelled $A$ and $B$ in this work. Each copper ion is coordinated to one water molecule, two tetrazole nitrogen atoms from the same ligand (but different rings) and two carboxylate oxygen atoms from two different ligands, each coordinating in a monodentate fashion. The two nitrogen atoms (N12A, N22A for Cu1; N12B, N22B for Cu2) and two oxygen atoms (O1A, O3A for Cu1; O1B, O3B for Cu2) form the base of the square pyramid and one water molecule (O1W for Cu1; O2W for Cu2) occupies the apical position in each complex. Each ligand, therefore, is coordinated to three $\mathrm{Cu}$ (II) atoms via their $\mathrm{N}-1$ nitrogen atoms of the tetrazole rings and its two carboxylate oxygen atoms. This correlates well with observations from the IR spectrum of $\left[\mathrm{Cu}(4)\left(\mathrm{H}_{2} \mathrm{O}\right)\right]\left(\mathrm{H}_{2} \mathrm{O}\right)_{2}$. There was no coordination observed to the pyrazine and tetrazole nitrogen atoms to form a five-membered chelate ring, which was somewhat surprising. The coordination geometries for molecules $A$ and $B$ are similar for all five comparable $\mathrm{Cu}-\mathrm{O} / \mathrm{N}$ distances, however, $A$ is slightly more distorted as compared to $B$, with Cu1$\mathrm{O} 1 \mathrm{~W}=2.212(5) \AA$ and $\mathrm{Cu} 2-\mathrm{O} 2 \mathrm{~W}=2.187(5) \AA$. . In addition there are two water hydrate molecules per copper entity and with four water molecules in the asymmetric unit (packing index $=71.1)$. The $\left[\mathrm{Cu}(4)\left(\mathrm{H}_{2} \mathrm{O}\right)\right]\left(\mathrm{H}_{2} \mathrm{O}\right)_{2}$ complex crystallises as a 2-D coordination polymer which extends along the $a$ - and $b$-axes directions. These sheets are further connected into a 3-D hydrogen-bonded network.
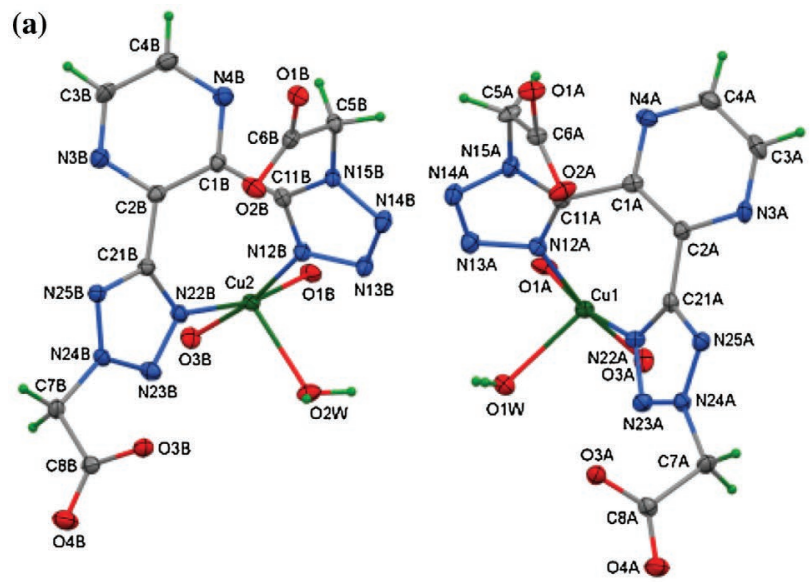

(c)

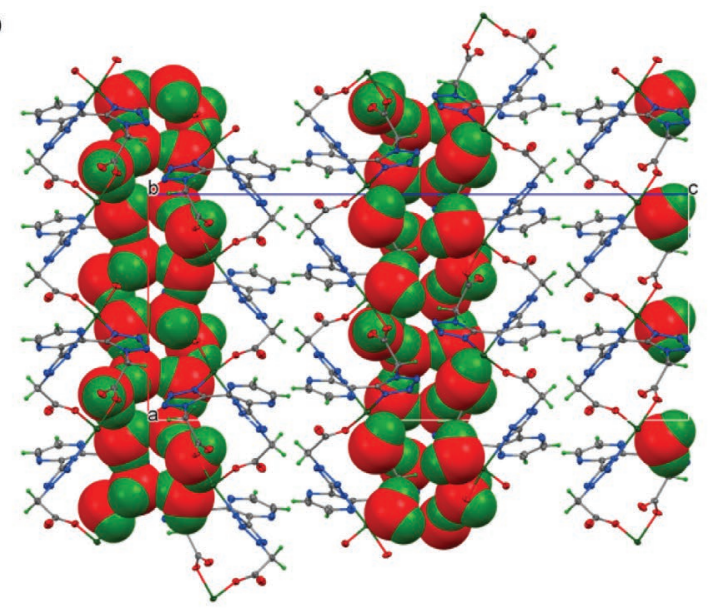

(b)



(d)

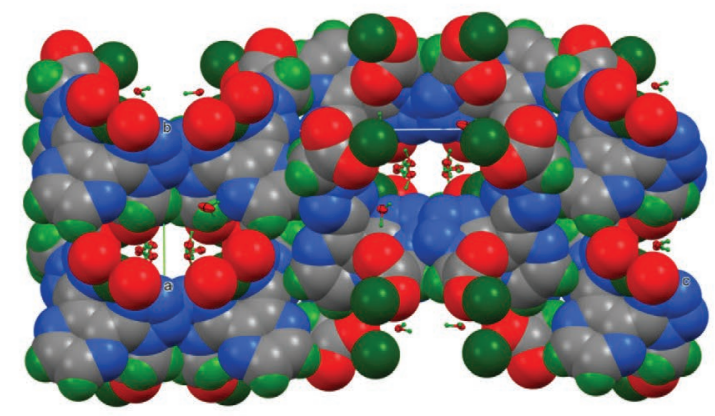

Figure 5. (Colour online) Molecules $A$ and $B$ in $\left[\mathrm{Cu}(4)\left(\mathrm{H}_{2} \mathrm{O}\right)\right]\left(\mathrm{H}_{2} \mathrm{O}\right)_{2}$ with Cu square pyramidal coordination geometry (completed by three symmetry related $O$ atoms) with views of molecules $A$ and $B$; views of the water channels with all six water molecules depicted as their van der Waals spheres and with a reverse CPK view (and rotated by $90^{\circ}$ ) along the $a$-axis direction. 
When compared to the crystal structure of the ligand $\mathbf{8}$, the coordination of the $\mathrm{Cu}(\mathrm{II})$ ion has the effect of puckering both tetrazole rings, but with relatively similar effects. However, the N-1 substituted ring is still more twisted relative to the $\mathrm{N}-2$ substituted ring (interplanar angles of $46.68(15)^{\circ}(\mathrm{N}-1)$ and $39.5(3)^{\circ}(\mathrm{N}-2)$ in molecule $A$ and with $48.54(15)^{\circ}(\mathrm{N}-1)$ and $36.9(3)^{\circ}$ for $(\mathrm{N}-2)$ in molecule $\left.B\right)$. The resulting seven-membered chelate ring is puckered due to this overall twisting.

We performed hybrid DFT calculations to determine the relative stability of the possible copper(II) coordination sites in the gas phase. Two minima were identified, one with the copper(II) tetra-coordinated in a distorted square planar conformation that involves the two tetrazoles (at $\mathrm{N}_{3}$ ) and two water molecules, see Figure $6(\mathrm{~b})$ and Table 1 (SI), and the other with the copper(II) penta-coordinated in a square pyramidal conformation that involves the pyrazine at $\mathrm{N}_{1}$, the tetrazole at $\mathrm{N}_{5}, 2$ water molecules, and one acetate group, see Figure $6(\mathrm{c})$ and Table 1 (SI). The penta-coordinated complex is the preferred conformation between the two, with a relative energy of $-15.9 \mathrm{kcal} / \mathrm{mol}$.

Based on an analysis of the structures deposited in the CSD, it is known that four-coordinate copper(II) complexes generally adopt geometries close to square planar four-coordinate (20). However, as shown in Figure 6(a), the asymmetric unit of the crystal structure shows the copper(II) coordinated to the two tetrazoles at $\mathrm{N}_{3}$ and to 1 water molecule in a trigonal pyramidal conformation. We think that the coordination in the crystal structure is actually tetrahedral, with the trigonally coordinated copper(II) making the base of the tetrahedron and with the fourth coordinating ligand provided by one of the water molecules from a neighbouring layer in the lattice. While not stable in the gas phase, a tetrahedral coordination is favoured in the solid phase as it allows close packing between the layers. While the chelation site between the two tetrazoles is structurally suited to distort into the tetrahedral conformation, we see in the crystal structure, the chelation site between the pyrazine and the tetrazole is too rigid to twist into this conformation.

A fascinating structural feature of $\left[\mathrm{Cu}(4)\left(\mathrm{H}_{2} \mathrm{O}\right)\right]\left(\mathrm{H}_{2} \mathrm{O}\right)_{2}$ is the clusters of water molecules that are present in the asymmetric unit (Figures 5 and 7) and this dominates the crystal structure. There is no disorder, but the O6W water molecule has large displacement ellipsoids and is held loosely in the crystal lattice relative to the other three water molecules. Both $\mathrm{O} 1$ and $\mathrm{O} 2 \mathrm{~W}$ acts as a double hydrogen bond donors and also participate as acceptors for two weaker interactions each (both $\mathrm{O} 1$ and $\mathrm{O} 2 \mathrm{~W}$ are coordinated to $\mathrm{Cu} 1$ and Cu2, respectively). Water hydrates $\mathrm{O} 3$ and $\mathrm{O} 4 \mathrm{~W}$ act as double hydrogen bond donor and double hydrogen bond acceptors and with $\mathrm{O5}$ and $\mathrm{O6W}$ acting as hydrogen bond donors and acceptor. The $0 \cdots O$ distances $(\times 6)$ within the hexanuclear cluster fall in the range of 2.708(8)-2.887(8) $\AA$ with an average value of $2.78 \AA$, as compared with $2.76 \AA$ (at $-90^{\circ} \mathrm{C}$ ) in hexagonal ice or $2.74 \AA$ in cubic ice (21). This cluster is also stabilised in the network through $\mathrm{O}_{\text {water }}-\mathrm{H}^{\cdots} \mathrm{O}_{\text {carboxyl }}$ hydrogen bonds. The average $\mathrm{O} \cdots \mathrm{O}$ distance for the 10 $(6+4)$ is $2.789 \AA$. Throughout the 2-D coordination sheet, the four crystallographically independent water molecules $(\mathrm{O} 1, \mathrm{O} 2, \mathrm{O} 3$, and $\mathrm{O} 4 \mathrm{~W})$ form hydrogen bonded to each other forming an infinite water chain with a curl conformation (Figure 6). The arrangement mode of the water molecules within the chain can be described as $[\cdots 02 \cdots 03 \cdots 01 \cdots 04 W \cdots]_{n}$. The overall $\left[\left(\mathrm{H}_{2} \mathrm{O}\right)_{4}\right]_{n}$ chain can be represented by $\mathrm{C} 4$, according to the water cluster nomenclature described by Infantes and co-workers(22). The literature relating to the structure of pure water in (a)

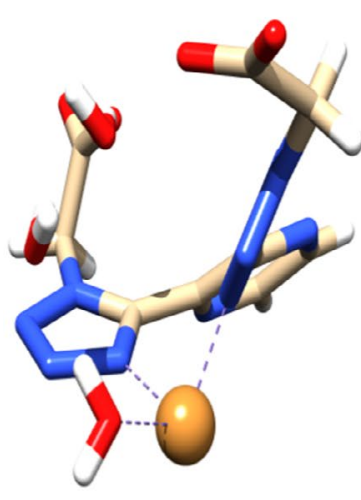

(b)

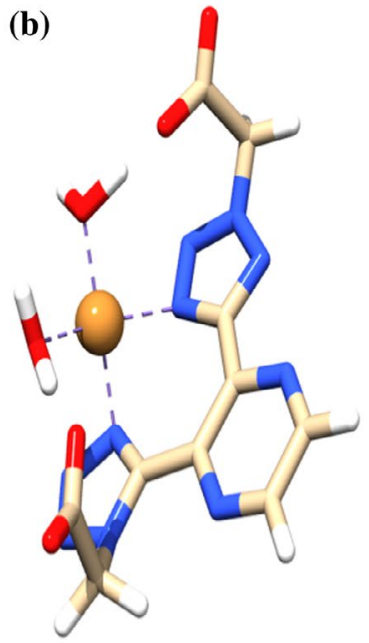

(c)

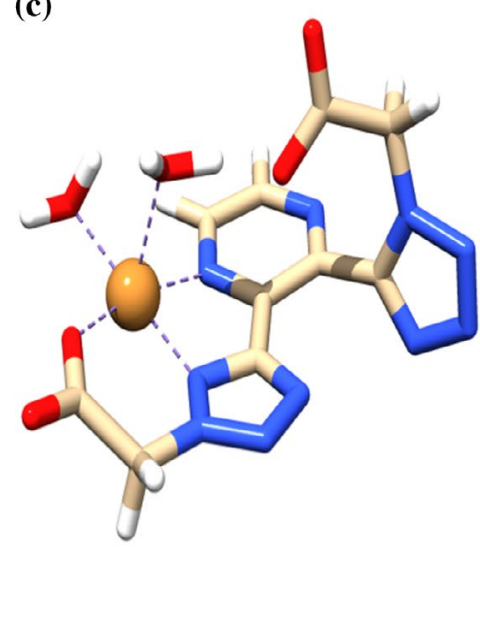

Figure 6. (Colour online) Panel (a) coordination of the monomer in the asymmetric unit. Panel (b) Gas phase square planar tetracoordinated minimum. Panel (c) Gas phase square pyramidal pentaccordinated minimum. 
Table 1. Crystallography data for $1,2,8,\left[\mathrm{Cu}(4)\left(\mathrm{H}_{2} \mathrm{O}\right)\right]\left(\mathrm{H}_{2} \mathrm{O}\right)_{2}$ and $\mathrm{Cu}(5)\left(\mathrm{H}_{2} \mathrm{O}\right)_{2}$.

\begin{tabular}{|c|c|c|c|c|c|}
\hline & 1 & 2 & $\mathbf{8}\left(\mathrm{H}_{2} \mathrm{O}\right)$ & {$\left[\mathrm{Cu}(4)\left(\mathrm{H}_{2} \mathrm{O}\right)\right]\left(\mathrm{H}_{2} \mathrm{O}\right)_{2}$} & $\mathrm{Cu}(\mathbf{5})\left(\mathrm{H}_{2} \mathrm{O}\right)_{2}$ \\
\hline $\begin{array}{l}\text { Chemical formula } \\
M_{\mathrm{r}} \\
\text { Crystal system, space } \\
\text { group }\end{array}$ & $\begin{array}{l}\mathrm{C}_{14} \mathrm{H}_{16} \mathrm{~N}_{10} \mathrm{O}_{4} \\
388.37 \\
\text { Triclinic, } P^{-1}\end{array}$ & $\begin{array}{c}\mathrm{C}_{14} \mathrm{H}_{16} \mathrm{~N}_{10} \mathrm{O}_{4} \\
388.37 \\
\text { Monoclinic, } P 2_{1} / n\end{array}$ & $\begin{array}{c}\mathrm{C}_{10} \mathrm{H}_{10} \mathrm{~N}_{10} \mathrm{O}_{5} \\
350.28 \\
\text { Monoclinic, } P 2_{1} / n\end{array}$ & $\begin{array}{c}\mathrm{C}_{10} \mathrm{H}_{12} \mathrm{CuN}_{10} \mathrm{O}_{7} \\
447.84 \\
\text { Orthorhombic, Pna2 }\end{array}$ & $\begin{array}{c}\mathrm{C}_{10} \mathrm{H}_{10} \mathrm{CuN}_{10} \mathrm{O}_{6} \\
429.82 \\
\text { Orthorhombic, } \mathrm{Cmc2}_{1}\end{array}$ \\
\hline Temperature (K) & $294(1)$ & $294(1)$ & $294(1)$ & $294(1)$ & $294(1)$ \\
\hline$a, b, c(\AA) \alpha, \beta, \gamma\left(^{\circ}\right)$ & $\begin{array}{c}9.1675(9), 10.0494 \\
(16), 10.9931(18), \\
111.875(15), 96.757 \\
(11), 99.887(11)\end{array}$ & $\begin{array}{c}8.6939(10), 7.8854(9) \\
26.452(3), 90,94.281 \\
(10), 90\end{array}$ & $\begin{array}{c}9.4877(4), 14.6258 \\
(7), 11.2459(5), 90 \\
105.206(5), 90\end{array}$ & $\begin{array}{c}12.3497(5), 9.0242(4), \\
29.5410(18)\end{array}$ & $\begin{array}{c}12.9001(5), 9.9112(5), \\
11.9877(5)\end{array}$ \\
\hline$V\left(\AA^{3}\right)$ & $907.4(2)$ & $1808.4(4)$ & $1505.90(12)$ & $3292.2(3)$ & $1532.69(12)$ \\
\hline$Z$ & 2 & 4 & 4 & 8 & 4 \\
\hline$\mu\left(\mathrm{mm}^{-1}\right)$ & 0.11 & 0.11 & 0.127 & 1.391 & 1.486 \\
\hline Crystal size (mm) & $0.55 \times 0.45 \times 0.20$ & $0.25 \times 0.10 \times 0.05$ & $0.32 \times 0.17 \times 0.08$ & $0.55 \times 0.35 \times 0.15$ & $0.77 \times 0.45 \times 0.03$ \\
\hline $\begin{array}{l}\text { No. of measured, inde- } \\
\text { pendent and observed } \\
\text { reflections }\end{array}$ & $8086,4698,3391$ & $12901,3982,1267$ & $10740,3408,2337$ & $27488,8420,7389$ & $5315,1789,1665$ \\
\hline$R_{\text {int }}$ & 0.022 & 0.12 & 0.048 & 0.043 & 0.025 \\
\hline$(\sin \theta / \lambda)_{\max }\left(\AA^{-1}\right)$ & 0.692 & 0.656 & 0.669 & 0.687 & 0.667 \\
\hline$R\left[F^{2}>2 \sigma\left(F^{2}\right)\right], w R\left(F^{2}\right), S$ & $0.055,0.158,1.03$ & $0.064,0.123,0.85$ & $0.048,0.135,1.07$ & $0.041,0.103,1.06$ & $0.037,0.096,1.09$ \\
\hline No. of reflections & 4698 & 3982 & 3408 & 8420 & 1789 \\
\hline No. of parameters & 256 & 256 & 241 & 543 & 134 \\
\hline No. of restraints & 0 & 0 & 0 & 19 & 3 \\
\hline $\mathrm{H}$-atom treatment & $\begin{array}{l}H \text { atoms treated by } \\
\text { constrained refinement }\end{array}$ & $\begin{array}{l}H \text { atoms treated by } \\
\text { constrained refinement }\end{array}$ & $\begin{array}{l}H \text { atoms treated by } \\
\text { both independent } \\
\text { and constrained } \\
\text { refinement }\end{array}$ & $\begin{array}{l}H \text { atoms treated using } \\
\text { independent and con- } \\
\text { strained refinement }\end{array}$ & $\begin{array}{c}H \text { atoms treated using } \\
\text { independent and con- } \\
\text { strained refinement }\end{array}$ \\
\hline$\Delta \rho_{\max ^{\prime}} \Delta \rho_{\min }\left(e \AA^{-3}\right)$ & $0.44,-0.30$ & $0.18,-0.18$ & $0.30,-0.22$ & $0.90,-0.59$ & $0.38,-0.44$ \\
\hline
\end{tabular}

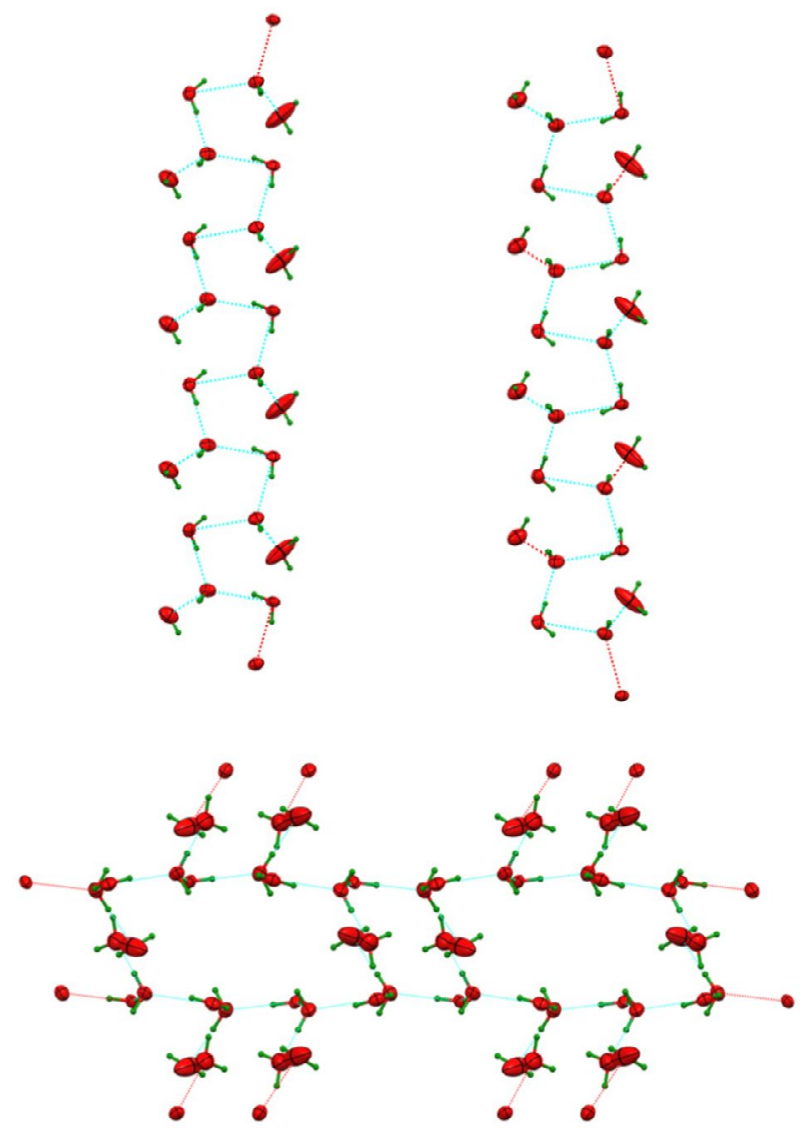

Figure 7. (Colour online) Views of the 1-D water chains in the unit cell as viewed along the $b$-axis and $c$-axis directions with blue dashed lines for intermolecular interactions. both the solid and liquid state as well as in mixed-component systems, is extensive (21). An improved understanding of the 3-D structural aspects of water has important implications in the area of structural biology. Several examples have demonstrated the importance of water structuring (23-25). It is thought that water molecules contribute to the complex stability by mediating hydrogen bonds between functional groups of the protein and the ligands, and by filling potential voids or holes inside the binding site (24). Given the influence of water on the structure and function of biological systems and its fundamental role in almost all branches of natural sciences it is not surprising that hydrogen-bonded water aggregates have received much attention. Accurate structural data of low-dimensional water structures are the key in the elucidation of the complex interplay of biological, chemical and structural properties of water, which is surprisingly still not fully understood. Coordination compounds, metal organic framework structures and suitable organic compounds can provide ideal void spaces to trap fractions of ice or other hydrogen-bonded water aggregates and these have been utilised to simulate water crystallisation in restricted environments (25). Over the years, such structures have been characterised and categorised (20); examples include defined oligomeric water aggregates $\left(\mathrm{H}_{2} \mathrm{O}\right)_{n}(n=2-100)(19,26), 1-D$ chains or tapes (27) and 2-D layered structures (28). An elegant example of water channels is the organometallic ferrocene salt $\left[\mathrm{Na}^{+}\right]_{10}\left[\mathrm{Fe}\left\{\eta^{5}\left(\mathrm{C}_{5} \mathrm{H}_{4}\right)-4-\mathrm{C}_{6} \mathrm{H}_{4} \mathrm{CO}_{2}\right\}_{2}\right]_{5} \cdot 3\left(\mathrm{H}_{2} \mathrm{O}\right)$ (derived from its 
diester) where water molecules aggregate forming 1D zigzag chains in the crystal lattice(29).

\subsection{Synthesis and characterisation of copper(II) complex of 2}

Reaction of ligand $\mathbf{2}$ and $\mathrm{CuCl}_{2} \cdot 2 \mathrm{H}_{2} \mathrm{O}$ in aqueous sodium hydroxide resulted in the formation of pale blue block-like crystals on standing for 1 day. The crystals were analysed by IR spectroscopy and elemental analysis and X-ray crystallography. The IR spectrum of the pale blue solid indicated that there was no protonated carboxylate present, and the presence of a $\nu_{\text {asym }}\left(\mathrm{COO}^{-}\right)$vibration at $1640 \mathrm{~cm}^{-1}$ and a corresponding $\nu_{\text {sym }}\left(\mathrm{COO}^{-}\right)$vibration positioned at $1380 \mathrm{~cm}^{-1}$ suggested that the deprotonated carboxylates were adopting a monodentate coordination to the metal
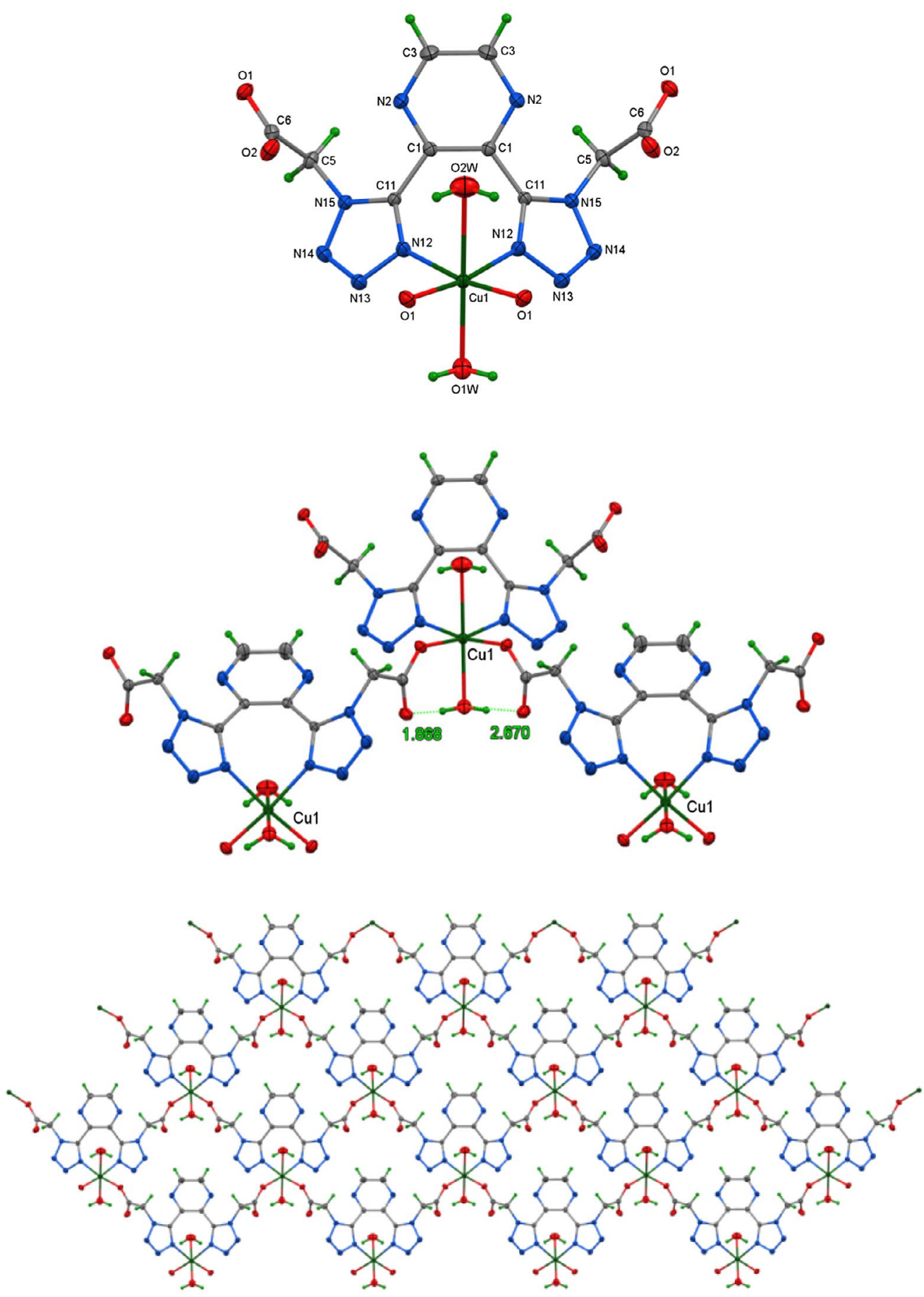

Figure 8. (Colour online) A view of $\mathrm{Cu}(5)\left(\mathrm{H}_{2} \mathrm{O}\right)_{2}$ with atoms depicted with $30 \%$ probability ellipsoids and highlighting the coordination geometry about the $\mathrm{Cu} 1$ atom (interaction distances) and a section of $\mathrm{Cu}(5)\left(\mathrm{H}_{2} \mathrm{O}\right)_{2}$ viewed along $b$-axis direction. 


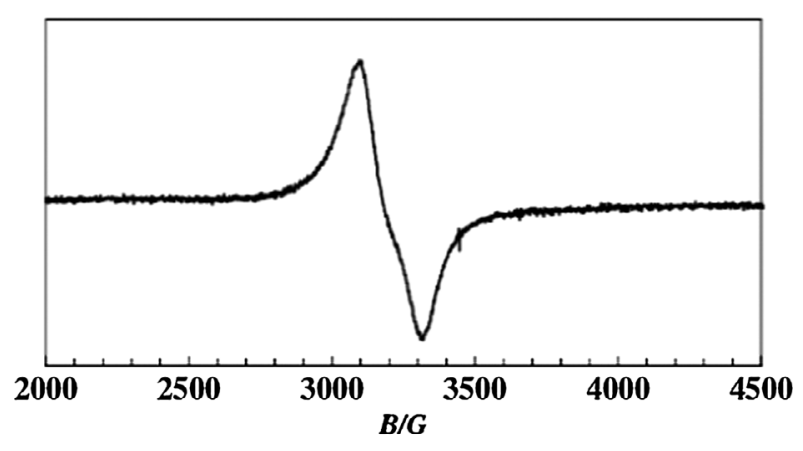

Figure 9. Room temperature 9.63 GHz EPR spectrum of a powder sample of $\left[\mathrm{Cu}(4)\left(\mathrm{H}_{2} \mathrm{O}\right)\right]\left(\mathrm{H}_{2} \mathrm{O}\right)_{2}, g_{\mathrm{x}}=g_{\mathrm{y}}=g_{\mathrm{z}}=2.19$.

centre. A broad stretch at $3050 \mathrm{~cm}^{-1}$ alluded to the presence of water in the structure. Elemental analysis of the blue solid suggested the compound had a 1:1 metal to ligand ratio and was postulated as $\left[\mathrm{Cu}(\mathbf{5})\left(\mathrm{H}_{2} \mathrm{O}\right)_{2}\right]$, which again confirmed that the ester groups had been removed from 2 to produce 5 in the complex. The crystal structure of $\left[\mathrm{Cu}(5)\left(\mathrm{H}_{2} \mathrm{O}\right)_{2}\right]$ reveals mononuclear subunits, with the $\mathrm{Cu}(\mathrm{II})$ ion in an octahedral environment. The equatorial plane of the octahedron is occupied by two tetrazole N-1 nitrogen atoms from the same ligand, two carboxylate oxygen atoms from two different ligands adopting a monodentate binding mode and two water molecules which occupy the axial positions. One of the water molecules O1W forms a short hydrogen bonding interaction with the carboxylate oxygen $\mathrm{O} 2$ forming a six-membered hydrogen-bonded ring $(\mathrm{O} 1 \mathrm{~W} \cdots \mathrm{O} 2=2.670(5) \AA)$. However, O2W does not perhaps in any classical hydrogen bonding and is at contact distances with a neighbouring symmetry related $N$ atom $(\mathrm{O} 2 \mathrm{~W} \cdots \mathrm{N} 14=3.407(4) \AA)$. The bonding arrangement leads to a 2-D coordination polymer, with each ligand bonded to three $\mathrm{Cu}(\mathrm{II})$ atoms (Figure 8).

Each asymmetric unit extends in two directions forming a 2-D coordination layer, propagating along the crystallographic $a$ - and $c$-axes (Figure 7); the packing index is 71.6. Despite the presence of coordinated water molecules, there are no classical hydrogen bonds observed between the sheets, and no other significant interactions are present. However, hydrogen bonding does exist between $\mathrm{O} 2$ and $\mathrm{O} 1 \mathrm{~W}$ and between $\mathrm{O} 1$ and $\mathrm{O} 2 \mathrm{~W}$ within the same 2-D sheet. To describe the topology of [Cu(5) $\left.\left(\mathrm{H}_{2} \mathrm{O}\right)_{2}\right]$, the underlying net can be described as having a four-connected topology with the $\mathrm{Cu}$ (II) centre acting as a four-coordinated node. The space surrounded by these nodes are filled by the pyrazine ring, however we believe that extending the length of the linker between the tetrazole ring and carboxyl group could expand the size of the molecules and increase the possibility of generating pores.

The X-band EPR spectra of $\left[\mathrm{Cu}(\mathbf{4})\left(\mathrm{H}_{2} \mathrm{O}\right)\right]\left(\mathrm{H}_{2} \mathrm{O}\right)_{2}$ and $[\mathrm{Cu}(\mathbf{5})$ $\left.\left(\mathrm{H}_{2} \mathrm{O}\right)_{2}\right]$ were measured in the solid state as powders at room temperature. Figure 9 displays the EPR spectrum of $\left[\mathrm{Cu}(4)\left(\mathrm{H}_{2} \mathrm{O}\right)\right]\left(\mathrm{H}_{2} \mathrm{O}\right)_{2}$, which resembles an isotropic signal, where $g_{\mathrm{x}}=g_{\mathrm{y}}=g_{\mathrm{z}}$. It was observed that this signal could have been overlapping with another signal. However, it was proposed that the crystallinity of the sample could perturb the signal (samples were ground, however crystalline particles always remained). The extracted $\mathrm{g}$ factor (2.191) was typical of a transition metal unpaired electron as it was much greater than the free electron $g$ value (30). An isotropic signal implies that the three principle axes are the same and on examination of the bond distances around the $\mathrm{Cu}(\mathrm{II})$ centres (which are all $\sim 2 \AA$ ) this was observed to be in agreement with the crystal structure obtained.

\section{Conclusions}

Bis-tetrazole ligands, containing carboxylate functional groups, were synthesised with a rigid pyrazine linker unit in order to examine the dimensionality of the resulting copper(II) containing CPs. The use of pyrazine as a linker unit was expected to increase the dimensionality of the resulting copper(II) containing CPs. X-ray structures of the ligands revealed the effect of the substitution position on the tetrazole ring of the ester/carboxylate groups. Higher dimensionality was successfully achieved with 2-D CPs being formed when the pyrazine bis-tetrazole systems were reacted with copper(II) chloride. The 2-D coordination polymer based on the asymmetric substituted pyrazine bis-tetrazole was further connected into a 3-D coordination network through hydrogen bonding between $\mathrm{H}_{2} \mathrm{O}$ molecules. These $\mathrm{H}_{2} \mathrm{O}$ molecules were connected as a unique 1-D chain throughout the structure. $\mathrm{H}_{2} \mathrm{O}$ aggregates in crystal hosts are gaining a lot of interest in recent years as they provide diverse environments in which to obtain precise structural information about the bonding properties of $\mathrm{H}_{2} \mathrm{O}$.

\section{Acknowledgements}

We are thankful to Maynooth University and to the Irish Research Council for financial assistance through the provision of a John \& Pat Hume Fellowship and a Postgraduate Scholarship, respectively (US). JFG thanks Dublin City University for grants in aid of research.

\section{Disclosure statement}

No potential conflict of interest was reported by the authors.

\section{Supplemental material}

Supplemental data for this article can be accessed online here: http://dx.doi.org/10.1080/10610278.2015.1123261 


\section{References}

(1) Bencini, A.; Lippolis, V. Coord. Chem. Rev. 2010, 254, 2096-2180; Knoll, J.D.; Turro, C. Coord. Chem. Rev. 2015, 282-283, 110-126; Novio, F.; Simmchen, J.; Vázquez-Mera, N.; Amorín-Ferré, L.; Ruiz-Molina, D. Coord. Chem. Rev. 2013, 257, 2839-2847; Bradberry, S.J.; Savyasachi, A.J.; Martinez-Calvo, M.; Gunnlaugsson, T. Coord. Chem. Rev. 2014, 273-274, 226-241; Xu, H.; Sun, Q.; An, Z.; Wei, Y.; Liu, X. Coord. Chem. Rev. 2015, 293-294, 228-249; BozicWeber, B.; Constable, E.C.; Housecroft, C.E. Coord. Chem. Rev. 2013, 257, 3089-3106.

(2) Medici, S.; Peana, M.; Nurchi, V.M.; Lachowicz, J.I.; Crisponi, G.; Zoroddu, M.A. Coord. Chem. Rev. 2015, 284, 329-350; Kulesza, J., Barros, B.S., Alves Júnior, S. Coord. Chem. Rev. 2013, 257, 2192-2212; Singh, A.K., Pandey, D.S., Xu, Q., Braunstein, P. Coord. Chem. Rev. 2014, 270-271, 31-56; Liu, J.-L., Chen, Y.-C., Guo, F.-S., Tong, M.-L. Coord. Chem. Rev. 2014, 281, 26-49; Masoomi, M.Y., Morsali, A. Coord. Chem. Rev. 2012, 256, 2921-2943; Klingele, J. Coord. Chem. Rev. 2015, 292, 15-29.

(3) Lu, W.; Wei, Z.; Gu, Z.-Y.; Liu, T.-F.; Park, J.; Park, J.; Tian, J.; Zhang, M.; Zhang, Q.; Gentle, T., IIl; Bosch, M.; Zhou, H.-C. Chem. Soc. Rev. 2014, 43, 5561-5593.

(4) Bhandari, S.; Mahon, M.F.; Molloy, K.C.; Palmer, J.S.; Sayers, S.F. Dalton Trans. 2000, 1053-1060.

(5) Dincă, M.; Yu, A.F.; Long, J.R. J. Am. Chem. Soc. 2006, 128, 8904-8913.

(6) Sheridan, U.; McGinley, J.; Gallagher, J.F.; Bjerrum, M.J.; Fleming, A.; Kelleher, F. Inorg. Chim. Acta 2014, 421, 200209; Sheridan, U.; Gallagher, J.F.; Philippidis, A.; McGinley, J. Inorg. Chim. Acta 2015, 432, 50-55.

(7) Steel, P.J.; Fitchett, C.M. Coord. Chem. Rev. 2008, 252, 9901006; Ellsworth, J.M.; Zur Loye, H.-C. Dalton Trans. 2008, 5823-5835; Rajput, A.; Mukherjee, R. Coord. Chem. Rev. 2013, 257, 350-368.

(8) Gaire, J.; McGinley, J.; Fleming, A.; Kelleher, F. Tetrahedron 2012, 68, 5935-5941; Li, J.-R.; Tao, Y.; Yu, Q.; Bu, X.-H.; Sakamoto, H.; Kitagawa, S. Chem. Eur. J., 2008, 14, 2771-2776.

(9) Oxford Diffraction Ltd. ABSFAC and CrysAlisPro CCD/ RED, Version 1.171.33.55, Oxford Diffraction, Abingdon, Oxfordshire, UK.

(10) Sheldrick, G.M. Acta Crystallogr. Sect. A 2008, A64, 11-122.

(11) McArdle, P.J. Appl. Cryst. 1995, 28, 65-65.

(12) Mocilac, P.;Tallon, M.; Lough, A.J.; Gallagher, J.F. Cryst. Eng. Commun. 2010, 12, 3080-3090; Mocilac, P.; Donnelly, K.; Gallagher, J.F. Acta Cryst. 2012, B68, 189-203.

(13) Macrae, C.F.; Bruno, I.J.; Chisholm, J.A.; Edgington, P.R.; McCabe, P.; Pidcock, E.; Rodriguez-Monge, L.; Taylor, R.; van de Streek, J.; Wood, P.A.J. Appl. Cryst. 2008, 41, 466-470.
(14) TURBOMOLE V6.2 2010. University of Karlsruhe and Forschungszentrum Karlsruhe $\mathrm{GmbH}, 1989-2007$.

(15) Schrödinger, L., Maestro, version 10.1, New York, 2015.

(16) Sorgi, K.L. In Encyclopedia of Reagents for Organic Synthesis, John Wiley \& Sons, Ltd: Chichester, 2001.

(17) Li, Q.-Y.; Yang, G.-W.; Tang, X.-Y.; Ma, Y.-S.; Zhou, F.; Liu, W.; Chen, J.; Zhou, H. Inorg. Chem. Commun., 2010, 13, 254257; Koguro, K.; Oga, T.; Mitsui, S.; Orita, R. Synthesis, 1998, 910-914.

(18) Ferguson, G.; Gallagher, J.F.; McAlees, A.J. Acta Cryst. 1995, C51, 454-458.

(19) Nakamoto, K. Infrared and Raman Spectra of Inorganic and Coordination Compounds: Applications in Coordination, Organometallic, and Bioinorganic Chemistry, 6th ed.; Wiley-Blackwell: New Jersey, 2009.

(20) Raithby, P.R.; Shields, G.P.; Allen, F.H.; Motherwell, W.D.S. Acta Crystallogr. B 2000, 56, 444-454.

(21) Han, L.-L.; Zhang, X.-Y.; Chen, J.-S.; Li, Z.-H.; Sun, D.-F.; Wang, X.-P.; Sun, D. Cryst. Growth Des., 2014, 14, 22302239; Eisenberg, D.; Kauzmann, W. The Structure and Properties of Water, Oxford University Press, Oxford, UK, 1969; Barbour, L.J.; Orr, G.W.; Atwood, J.L. Nature 1998 393, 671-673.

(22) Infantes, L.; Chisholm, J.; Motherwell, S. CrystEngComm 2003, 5, 480-486; Infantes, L.; Motherwell, S. CrystEngComm 2002, 4, 454-461.

(23) Royer,W.E.; Pardanani, A.; Gibson, Q.H.; Peterson, E.S.; Friedman, J.M. Proc. Nat. Acad. Sci. USA. 1996, 93, 14526-14531.

(24) Baker, E.N. J. Mol. Biol. 1980, 141, 441-484.

(25) Liljas, A.; Kannan, K.K.; Bergsten, P.C.; Waara, L.; Fridborg, K.; Strandberg, B.; Carlbom, U.; Jarup, L.; Lovgren, S.; Petef, M. Nature (London) New Biol. 1972, 235, 131-137.

(26) Quiocho, F.A.; Wilson, D.K.; Vyas, N.K. Nature 1989, 340, 404-407.

(27) (a) Keutsch, F.N.; Cruzan, J.D.; Saykally, R.J. Chem. Rev. 2003, 103, 2533-2578; (b) Pal, S.; Sankaran, N.B.; Samanta, A. Angew. Chem. Int. Ed. 2003, 42, 1741-1743.

(28) Lakshminarayanan, P.S.; Suresh, E.; Ghosh, P. Angew. Chem. Int. Ed. 2006, 45, 3807-3811.

(29) Jin, Y.; Che, Y.; Batten, S.R.; Chen, P.; Zheng, J. Eur. J. Inorg. Chem. 2007, 1925-1929.

(30) Oxtoby, N.S.; Blake, A.J.; Champness, N.R.; Wilson, C. Chem. Eur. J. 2005, 11, 4643-4654.

(31) Gallagher, J.F.; Alley, S.; Brosnan, M.; Lough, A.J. Acta Crystallogr. B 2010, 66, 196-205.

(32) Drago, R.S. Physical Methods in Chemistry, 1st ed.; W. B. Saunders Company, Philadelphia, PA, 1977. 
Copyright of Supramolecular Chemistry is the property of Taylor \& Francis Ltd and its content may not be copied or emailed to multiple sites or posted to a listserv without the copyright holder's express written permission. However, users may print, download, or email articles for individual use. 